\title{
Neither 'bolt-on' nor 'built-in': benefits and challenges of developing an integrated skills curriculum through a partnership model
}

\author{
James Cairns \\ University of Sheffield, UK \\ Tamara Hervey \\ University of Sheffield, UK \\ Oliver Johnson \\ University of Sheffield, UK
}

\begin{abstract}
All universities are seeking to develop their students' skills. Typically, they deploy either or both an independent 'skills' offering, separate from disciplinary learning ('bolt-on'); and/or individual academic staff embedding skills assessment in some modules ('built-in'). What are the drawbacks of 'bolt-on' and 'built-in'? To what extent does a partnership model, involving an integrated and longitudinal skills curriculum, resolve those drawbacks? Under what circumstances is this possible? What are the main barriers? We present a case study of a major curriculum development in the School of Law at the University of Sheffield to argue that the benefits of partnership probably outweigh either 'bolt-on' or 'built-in'. However, some of the enablers and inhibitors associated with contemporary higher education (HE) may suggest that 'built-in' is more viable. This is not primarily because of the difficulties of engaging academic disciplinary specialists; rather it is better explained by structural and institutional rigidities. We therefore recommend courage to take a long view, to aim high, and to celebrate small successes.
\end{abstract}

Keywords: skills; employability; student partnership; reflective practice. 


\section{Introduction}

In 2006, Ursula Wingate argued that 'study skills' should not be 'bolted-on' to undergraduate curricula, but 'built-in' to substantive disciplinary teaching. She concluded that 'a realistic and effective approach for universities would be to promote the embedding of skills on a smaller scale, by encouraging academic staff to integrate the development of learning into their teaching' (Wingate, 2006, p.467). We agree with Wingate that 'boltingon' opportunities for undergraduate students to develop their academic, disciplinary and transferable skills is a profoundly unsatisfactory approach, but we also think that simply relying on the goodwill of individual academics to 'build in' skills development misses important opportunities to develop integrated skills curricula through partnership between disciplinary experts, skills learning and teaching experts, and students themselves. In short, we are arguing for neither 'bolt-on', nor 'built-in', but blended together in partnerships that involve mutual respect for different types of knowledge, experience and expertise. The following case study of a major curriculum development in the School of Law at the University of Sheffield explores this proposition. The curriculum development we describe involves around 950-1000 undergraduate students each year, and around 100 members of staff, both academic and professional services staff, in the School of Law and elsewhere in the University. We provide a reflective analysis of the challenges, pitfalls and successes associated with the design and delivery of such a large-scale partnershipbased learning model.

\section{Background}

The ongoing marketisation of the higher education (HE) sector in recent years has transformed the term 'student experience' into a contested zone that, on the one hand, describes the transformative nature of an undergraduate degree programme and its associated impact on lifelong learning and, on the other, quantifies the value of a degree programme according to a set of basic metrics (Brown and Carasso, 2013; Molesworth et al., 2010; Hockings, 2010). At the same time, student recruitment has become the sector's primary financial driver, placing pressure on academic departments to meet stringent targets and seek opportunities to widen the undergraduate admission base. Already highlighted in Wingate's research over 10 years ago, and far from unique to the UK (e.g. Pritchard et al., 2015), these pressures have only intensified with the further diversification 
of the HE sector in England and Wales, alongside the introduction of the Teaching Excellence Framework, with its Key Performance Indicators including student experience, as measured through the National Student Survey.

We replicated Wingate's (2006) search of university websites, also using a randomlychosen sample of 10 pre-1992 and 10 post-1992 universities. We found that all offer some kind of 'bolt-on' study skills programmes through bespoke units outside academic departments. Writing, note-taking, revision, and oral presentations still top the list of skills being taught this way. In several instances, skills are explicitly linked to future employability. Teaching offered is also often explicitly associated with skills not already acquired through secondary education with a focus on transition to the UK HE environment and the tacit knowledge associated with its assessment conventions.

The limitations of the 'bolt-on' approach are well-known (Thies, 2012; Wingate, 2006; Biggs, 2003; Durkin and Main, 2002) and need only be summarised briefly here. A deficitfocused model associates skills learning with failure, thus often deterring the very students it seeks to reach. Students do not perceive stand-alone skills teaching as relevant or transferrable to success on their disciplinary programmes. Nor do they consider that nonsubject experts have anything valuable to teach them. Above all, the 'bolt-on' model ignores the established insights of experiential learning (Kolb and Fry, 1975; Kolb, 2015): learning happens when there are opportunities to act in response to a meaningful problem or challenge; receive (external, peer or self) feedback on that action; and reflect on that process.

For all these reasons, the partnership model we recommend adopts an approach that conceptualises the skills at issue as blended with (rather than separate from) a body of knowledge; understands knowledge, skills, and learning as inherently subjectively determined; and above all seeks to develop reflection.

\section{Context}

The University of Sheffield has made a recent institution-wide shift towards a programmelevel view of student learning that acknowledges the limitations of modular teaching and seeks to improve baseline academic and transferable skills of an increasingly diverse body 
of undergraduate students (Chappie and Tolley, 2000; Fallows and Steven, 2000; Chadha and Nicholls, 2006). In common with several other universities, the University of Sheffield has increased both the resourcing and visibility of skills teaching through a bespoke unit, known locally as '301' because of its address at 301 Glossop Road in the heart of the campus.

Evidence from the early years of 301's activity supports existing literature on the limitations of a bolt-on stand-alone skills centre model as an approach that reaches a relatively small proportion of students. Deployment of resources on voluntary attendees has a high impact on those individuals, but a limited impact across the institution as a whole. In particular, a key target demographic of middle-achieving home undergraduate students is underrepresented through a voluntary or extra-curricular model of engagement, in spite of the reported prevalence of challenges around assessment literacy and skills development within this group (Stevenson and Clegg, 2011). Further, student perceptions of skills development as part of a wider employability agenda pull against 'context-transcendent' perceptions of learning and teaching (Kreber, 2010; Poole, 2010). Evidence from law students suggests low voluntary uptake of skills teaching is explained by the way student identities are rooted in department, disciplinary and professional 'silos', creating a barrier to engagement beyond the law school (Francis, 2015).

Given this evidence, collaborations with academic departments, such as Sheffield Law School, are welcomed by learning developers at 301 as opportunities to bridge the gap between disciplinary and 'generic' learning. A collaborative, partnership approach between stand-alone skills centres and academic departments opens the door to a two-way sharing of knowledge and expertise that allows both partners, and students, to benefit (MacVaugh et al., 2013; Gretton et al., 2015). Including students in the partnership offers important insights into lived student experience (Dickerson et al., 2015; Healey et al., 2014; Brown, forthcoming). The partnership model under discussion here attempts to strengthen and build on this triangular relationship between disciplinary experts, learning developers and students to broaden and enrich student and staff perceptions of where and how disciplinary learning takes place. The drive for the partnership model, relatively unusual in a research-intensive university, came from engagement with the literature that demonstrates the benefits of such a model: in other words, the pedagogical design behind the curriculum reform was itself research-led. For this to happen, it was necessary for at least some (senior) academic staff in the relevant disciplinary unit to engage actively with 
the pedagogical literature, both pertaining to the specific discipline of law, and more general. Commitments to research-led learning, understood in this way, helped to secure the continued success of the model in its institutional cultural contexts.

The development of a new undergraduate curriculum in Sheffield Law School in response to external professional sector reform (Legal Services Act 2007; Legal Education and Training Review, 2013) provided an opportunity for a break from past path dependencies (Pierson, 2000; Pierson and Skocpol, 2002), determining the ways undergraduate law programmes in English research-intensive universities were typically designed. This juncture provided the impetus to bring together skills and knowledge learning in a new unified framework, known as the 'Skills and Values Spine' because it is the 'backbone' of the curriculum. The Spine conceptualises undergraduate law student skills development as rooted in disciplinary and profession-formational reflective practice. The partnership approach was thus embedded from the outset.

\section{Designing the 'Skills and Values Spine': partnership chosen over 'built- in' and 'bolt-on'}

The underlying concepts for Sheffield Law School's 'Skills and Values Spine' are reflection and partnership. A common caricature of discipline-specific academic staff is that they have little understanding of, or respect for, the discipline of pedagogy, or pedagogical expertise. To the extent that this represents some truth, discipline specialists do not always recognise a need for input from specialists in learning development, or a responsibility to teach or assess skills. Likewise, students have chosen an academic discipline and, in the case of law, many have chosen a future profession. Many of those students believe that only discipline-specific academic staff can teach them what they need or want to know to acquire the skills and knowledge associated with that degree and profession. One of the benefits of partnership over 'bolt-on' is the way it helps overcome potential resistance from (some) staff and students. To overcome these potential barriers, we reframe the dynamic as an opportunity for research-led partnership and collaboration. According to this philosophy, all staff (both disciplinary and specialist skills development) and students involved in the Spine (and hence, implicitly, in the entire UG curriculum) are conceptualised as co-learners rather than teachers and pupils. 
In order to initiate this process, all academic staff in Sheffield Law School (around 65 individuals) were involved in initial discussions to identify a list of 'skills I would like the students to have but which I do not have space/time to teach, give feedback on, or assess in my module'. This mapping process, which also drew on student feedback at a modular level, and focus groups undertaken by the School, helped to highlight gaps in both provision and expertise, and resulted in an early draft of a skills pathway that would draw on both disciplinary expertise and professional skills input into areas including assessment literacy, reflection and employability. With the gaps in coverage and expertise established, it was possible to demonstrate both a pragmatic and a research-led need to draw on existing institutional resource and to build a collaborative 'task force' involving both department, student and professional services representation. Convincing senior academic staff in the School of the necessity of operating in this way was essential to the development of the model. The Spine 'lead' (Hervey) repeatedly asserted that her competencies and capacities were (and would always be) insufficient to develop the Spine alone: the partnership followed as a logical consequence.

The Skills and Values Spine was rolled out over the course of a four-year period. After an initial phase in which the broad structure, underlying principles, and outline of content were developed, each subsequent phase was associated with learning in a particular year of the programme. Ongoing reflection and review continues, drawing on the expertise of the partners as their respective expertise determines. The perspectives of undergraduate interns, alongside other data from student experiences, informed the design in a recursive process which involved close collaboration with subject specialist staff and staff with particular expertise in skills development from across the university. In keeping with the overall design, every learning event (independent learning hosted through the Virtual Learning Environment (VLE), peer-led group learning, tutorial, workshop or lecture) has been co-produced by at least two, and usually three, of the partners. Without the partnership, it would have been impossible to develop those learning materials. For example, a lecture and associated independent study on academic written registers for lawyers draws on generic knowledge (such as the 'fog' index of complexity (Gunning, 1952)), specific examples of law student assessments, and published legal research.

The Skills and Values Spine in Sheffield Law School takes institutional form as three zerocredit, year-long modules, delivered through a structured suite of learning events that support curricular learning on the School's nine 'qualifying law degree' programmes. The 
unit of learning event begins from the individual, and builds up to the whole cohort. Guided independent and small peer group learning is hosted on the VLE, and begins from 'Intro Week' before formal classes begin. A team of 15-25 Level 2, 3 and 4 students are recruited each year by a student-tutor leader (also a student) to support small group peer learning. These student tutors become natural ambassadors for the Spine, translating the value of the learning involved to students in younger cohorts. To develop independence, small group tutorials (4-5 students) with discipline-specific staff take place six times in the first year, and twice in each of the second and final years. The School's existing personal/academic tutoring system was deployed to deliver this aspect of the Spine. As staff were required to meet their tutees in any event, there was little increase in staff time costs: the Spine simply gives an agenda for those encounters.

Both transferable (employability) and disciplinary academic skills development, as well as discursive activities on values such as diversity or equality, take place in 'cafe style workshops' led by 2-3 staff. To build community, each cohort meets for a weekly lecture series provided by discipline-specific staff, specialist skills development staff with a range of expertise (including, for instance, information technology, research, time management, literacy, numeracy), students (for instance, reporting on research projects undertaken with law firms in other jurisdictions as part of a year abroad), and external speakers from the legal profession.

All of the learning events cross-refer each other, the programmes which they support, disciplinary and graduate competencies and capacities, and the 'skills and values' of a law graduate from a Russell-Group institution. They form a unified whole and would be significantly diminished if disaggregated into free-standing events. This means that staff who teach on the programme need to understand not only the specific topics/skills they teach, but also how these fit within the programme as a whole. The overall structure, including the key aspects of skills/values development involved in each element, is encapsulated on a shared spreadsheet, accessible to all staff and students involved. Each lecturer is briefed either by the Spine lead or the student tutor lead in advance of giving a lecture. The academic/personal tutors are briefed by a full learning objectives document associated with each tutorial. The Spine is also regularly discussed in teaching team meetings and - because it covers all programmes - assessment and programme review discussions mandated by QA processes. 
The decision to make attendance at all components of the programme compulsory was based on the need to ensure that all students engaged fully. This was both for QA purposes (some elements of the QA benchmark for law in Sheffield's undergraduate law degrees are only covered in the Spine) and to counter the 'deficit model' associated with skills teaching by conceptualising the programme of learning as a backbone integral to the success of all students (Lea and Street, 2006; Ganobcsik-Williams, 2004). The framing is directed mainly at students. Qualitative feedback on the Spine suggests that it is effective for a critical mass of students from the beginning of their studies, and that an increasing proportion of students understand the ways in which skills and values learning on the Spine supports their modular learning as they progress through their studies. Postgraduate students who support the Spine's peer learning invariably understand this framing. 'Zero-credit' was perceived as essential in order to accommodate professional and discipline-specific degree content, particularly in the bi-disciplinary LLB (Law and Criminology). The data on our case study must be seen in the context of this institutional form: for instance, a persistent minority of student feedback on the programme suggests resentment at being required to undertake learning in the context of a zero-credit module, and at being required to attend. Even the label 'module' may trigger particular expectations from students or staff, but university QA, timetabling and other systems mean that designating the Spine a 'module' was a pragmatic way to realise it within the constraints of existing systems and processes.

The principal learning outcomes from the Spine may be summarised as developing students as reflective independent learners, equipped for employment as law graduates. Students are assessed by an annual individual reflection on progress, against a selfdetermined set of aims. Students are asked 'what do you want to get out of your law degree at the University of Sheffield?', by reference to competency statements in the QAA Benchmark, and of relevant professional organisations, as well as private sector graduate employers, inside and outside the legal sector. Students are guided to conduct an individual competency audit and encouraged to make a concrete plan as to how they will achieve their self-set aims. The programme of learning on the Spine is placed in the context of the rest of the university experience. Connections and interactions between development of skills and consideration of values within the Spine, and 'for-credit' learning, as well as extra-curricular activities, are made explicit and constantly stressed. Students are explicitly taught about reflective practice in general (Kolb, 2015; Gibbs, 2013; Moon, 2009; Schön, 1984) and among lawyers (Hinett, 2002; Rue et al., 2013; Casey, 2014), and 
are encouraged to reflect on their development as they revisit particular disciplinary and transferable skills through the learning activities on the Spine. Once a year, students reflect formally on their progress towards those aims and are graded fail, pass, merit, or distinction on that reflection. In the first and final years, the grading is by the academic tutor. To develop transferable group work skills, in the second year grading is by peers. Students must pass the Spine in order to progress to the next year. To date, no student has failed.

\section{Reflections on and analysis of student and staff perceptions of the model}

One of the biggest challenges the case study faces is securing sufficient valuable feedback from students or staff as the Spine is rolled out in the new curriculum. We supplemented its original questionnaire-based, quantitative approach to evaluation, because less than a third of the first cohort (approximately 100 responses out of 350 students) gave any feedback at all, supplementing it with a more discursive and qualitative student focus group approach after the initial phase of development. We gathered further data during later development phases. This comprises responses from three sets of student focus groups, of around 10-15 students each, and reflections from around a dozen student interns who worked on the three development phases, as well as from staff in semi-structured interviews. The staff data was especially valuable as the staff were the audience for the students' self-reflective presentations which formed the assessment for the Spine. They thus provided a rich source of data on the student experience and learning, demonstrating that students were able to articulate themselves as developing reflective learners. The project has ethics clearance from the University of Sheffield's standard research ethics processes. The analysis below should be approached with these limitations of our data in mind.

Whilst the absence of a proactive student response to requests for feedback broadly suggests an absence of acute discontent, it also implies a more troubling apathy towards the Spine, perhaps stemming from its compulsory zero-credit (i.e. high-commitment, lowstakes) character, but also perhaps relating to a deep-rooted ambivalence towards skillsbased learning. Equally, some attempts to have discussions among the staff teaching team have been met with indifference, with only a few members of academic staff 
expressing strongly-felt negative views, mostly about the lectures as a key learning mode in the Spine, or expressing views that demonstrated that the staff member was unaware of the totality of the Spine ('Why haven't you included teaching on X?' 'We have.'). In the case of both staff and student engagement with the Spine there is evidently ongoing work to be done to encourage a sense of shared ownership. Each new student cohort must by definition be brought within the partnership, and the student-tutors play a significant ambassadorial role here. This work continues and includes one-to-one engagement with key academic staff, for instance, who lead core modules, or who are programme directors. However, the majority of staff in these roles are already engaged with and committed to the Spine.

\section{Successes}

Students and staff report that the model delivers a reliable baseline of learning in the early weeks of transition from secondary (or further) education for all undergraduate law students: a cohort of 280-400 depending on the year's intake, from a range of backgrounds, countries and previous educational experiences. Students see this part of the curriculum as discipline-specific, rather than generic skills focused, even though all the key 'bolt-on' type skills (and others, such as group work) are covered during this initial phase of the programme:

I enjoyed the fact that we were introduced to the key concepts of the first year in a fun and engaging manner through the cafe style days - for example how we were introduced to the doctrine of judicial precedent. (Student questionnaire)

However, some students find at least some skills practice challenging:

I didn't like the pressure of standing up in front of the whole cohort to answer a question. (Student questionnaire)

Students and staff appreciate the blending of skills-focused learning alongside subjectspecific learning, and especially assessment, in the 'for-credit' modules. The quotations below show how the Spine's content supports modular discipline-specific learning. The first refers to the transitional learning of the first two weeks of the programme, which is designed to secure awareness of the attributes of HE learning for all students in the 
cohort, irrespective of their previous educational experiences. The second concerns the design of the Spine and the ways in which it develops academic, disciplinary, and transferable skills in a way that tracks modular learning and assessment:

The opportunity to embed introductory lectures in contract and tort law in the transitional 'English legal system' teaching is very welcome. (Staff feedback, interview)

The topics, lecture and tutorials have been organised in a useful way due to the fact that at times they corresponded to other modules (for example - the WINS lecture on how to approach a contract problem question for the purposes of the obligations exam). (Student focus group)

Students prefer lectures giving direct exam advice more than any other type of lecture included in the programme, but learning that integrates student reflection on professional values is also appreciated, as the following exemplifies. The student appreciates lectures explicitly focused on disciplinary assessment styles ('problem questions and essay questions'), but also the values aspects of the Spine, designed to inculcate reflection on the values associated with law graduates:

The lectures which explained the appropriate methods to use in order to write effective answers to problem questions and essay questions. I also really enjoyed the lectures on Equality and Justice, as anything to do with Equality and Justice really interests me. (Student questionnaire)

In general, student feedback suggests that the majority of students' temporal frame is the immediate term, within an atomistic context - how an individual student can graduate with the best possible law degree. There is a generally positive reaction to the Spine as preparation for the law degree (40.4\% agreeing/strongly agreeing and $29.8 \%$ of level 1 students neither agreeing nor disagreeing with this proposition). Level 3/4 students (engaged as peer tutors) had a stronger positive reaction: almost all expressed clear understanding of the programme as developing skills needed to succeed in a law degree. A typical sentiment is: 
I really wish we had had this kind of opportunity in my first year to learn about how to apply skills across different modules. It's helping me now, even though it is a bit too late. (Student focus group)

Around one third of students feel that the Spine is preparing them well for their future career; one third feel it is not; and a third neither agree nor disagree. The immediate term focus is stronger in feedback from level 1 than level 2 students, more of whom are also thinking about what will contribute to transferable skills to get a job. Moreover, level 1 students in particular tend to think the point of a law degree is narrower than the wide variety of careers available after graduating.

The programme thus to some extent engages and inspires students in the interplay of contextual versus 'context-transcendent' perceptions of learning and teaching towards the goal of 'employability, civic responsibility and lifelong learning as general graduate outcomes' (Kreber, 2010, p.7). This is evidenced by an increased engagement among level 1 Law School students with additional voluntary skills development opportunities offered by 301, the Careers Service, English Language Teaching Centre and Enterprise Unit, suggesting that the Spine has had a positive impact on student independence and awareness of the wider university learning environment. In this regard, the Spine takes seriously (including through adopting and deploying a single set of skills icons or 'badges') the advice that 'it would be more helpful for students' long-term development if the skills that are needed for studying effectively at university were presented and taught as the starting point in the development of those skills that are required from graduates. The same categories should be used for skills that are needed for academic study and employability' (Wingate, 2006, p.461).

Staff in particular appreciated the convergence of research, teaching, and co-curricular opportunities, and the development of the role of 'personal tutor' beyond pastoral support, to a relationship that supports the development of disciplinary and transferable skills, and reflective practice:

I like that I now know my personal tutees, having had academic interactions with them, rather than 'how are you doing?' encounters. (Staff interview) 
Staff report a high degree of satisfaction with the reflective presentations that form the assessment, as well as with development of core skills by the cohort as a whole. For example, several staff members commented on enhanced written communication skills (e.g. expressed in e-mails) compared to previous cohorts. Students welcomed their relationships with tutors, praising the following in the student questionnaire:

Having chance to go over things with personal tutor.

My personal tutor, he's very good.

My tutor... has been helpful in the sessions with any difficulties I have faced over the year.

Outside the department, 301 report a significantly higher engagement of law students with their services than in previous years. This pattern is also found in other 'external' university units, in particular the Careers Service, who are also partners in the development and delivery of the Spine. The Law School's approach has attracted attention from across the university, with the partnership approach taken by Law having an influence on programme level review in other social science departments, and in the Faculties of Engineering and Medicine and Dentistry. One of the key vectors in disseminating information about the Law School's partnership approach is the university's annual Learning and Teaching Conference, at which students and staff engaged in developing the Spine have presented work in progress.

Where student dissatisfaction was expressed, it was focused on the lectures, suggesting that perhaps students are more keen to 'learn by doing' than by passively absorbing information, and that the guided self- and peer-learning elements of the Spine are its most successful aspect.

Above all, in assessing the successes of the Spine, we report that students generally engaged with the self-directed learning tasks set, met in their peer groups to undertake guided learning, attended tutorials, cafe-style workshops and lectures, and completed the work: even though none of it was 'for-credit':

My peers seemed to like it both at the time and in retrospect. (Student tutor focus group) 


\title{
Challenges and limitations
}

Students give mixed accounts of their understandings of the relevance of lectures/tutorials and other learning in the Spine:

Lessons (sic) were well structured and planned with engaging material and interesting topics.

Each stage and lecture seems to be in line with the former. The opportunities given to us to say what we want to be discussed during the next lecture, gives us the opportunity to tell our problems and get solutions.

\begin{abstract}
A lot of the content seemed unnecessary, time would have been better spent elsewhere.
\end{abstract}

I thought a lot of the lectures especially the early ones e.g. about the history and diversity of the law school were irrelevant. Also I do not find the skills development theme of the tutorials useful.

(Student questionnaires)

As noted above, lectures, and their compulsory nature, along with the non-credit-bearing nature of the Spine and its associated workload, were singled out for particular criticism:

Most lectures were not relevant and was a shame to be the only compulsory lecture when lectures that are examined with credits are not. (Student questionnaire)

Feedback from students, and to some extent from staff, suggests that the aim of blending skills and disciplinary specific learning is difficult to communicate effectively. Timetabling and resourcing constraints mean it is not always feasible to map learning in the Spine to exactly contemporaneous student learning in 'for-credit modules', and this becomes more difficult at level 2 and almost impossible at level 3 because of the optionality of the degree structure at higher levels. In any event, part of the design is to demonstrate how skills learned in the context of one body of (legal) knowledge can be transferred to others. Information flow to disciplinary staff can also be a challenge, even where they are in principle willing to draw explicitly on learning in the Spine in their modular teaching. The 
scale of the department and staff perception of the multitudinous contemporary pressures on staff time may also be relevant here. Given students' short-term timeframes in respect to their perceived needs (and expressed (dis)satisfaction), this is an insurmountable challenge, because one of the aims is to prepare students for the longer term, even if students themselves are resistant to that preparation (Hervey and Wood, 2016). To the extent that it refuses to pander only to students' short-term desires, the model therefore has inbuilt dissatisfaction among some students, which renders it vulnerable at a time when the NSS is gaining greater currency. Moreover, although staff delivering the Spine are requested to make explicit the embedded links to disciplinary learning, and future employability or more general personal development, it is not possible to ensure that this is the case universally across the student experience, as staff 'buy-in' to the pedagogical design of the programme varied:

Had two tutors, for my tutor group and another group in the same session, one tutor did not know what work was set and did not seem to see the relevance of the module whilst the other took it seriously. Very conflicting and confusing. (Student questionnaire)

Student-led learning is central to the ethos and the success of the model. The associated reframing of staff and students as co-learners, rather than teachers and pupils, represented an unexpected challenge. The reframing is both for pedagogic and epistemological reasons, discussed above, and also for practical reasons, as in a large research-led law school disciplinary expertise differs significantly between staff. In addition, Sheffield Law School's professional strand and its internationalisation strategy meant that commonality of disciplinary expertise could not be assumed even at the level of a jurisdiction or core job function: not everyone in the department has an English law degree, and not everyone is research-active. Yet the programme's success depends upon (almost) everyone in the department tutoring on it, to deliver small group learning experiences. The original design of the Spine was to make a virtue out of this diversity of experience, and for all staff to model learning and reflection. The programme thus frames everyone (staff and students alike) as having something to learn, but this feature was read by some staff as implying deficiency in themselves. Responding to that perceived vulnerability meant, for instance, that 'lesson plans', making explicit the learning objectives for tutorials in great detail, originally designed to be shared with students, are now released to staff only. Another related challenge is enabling discipline-specific staff to feel 
sufficiently confident to promote student learning and reflection on what they perceive as (sub)discipline specific values (such as, for instance, equality or ethical lawyering) and generic skills. This challenge again relates to the fact that the epistemological assumptions on which the programme is based (in this case, the constructed nature of knowledge and the indivisibility of skills and knowledge learning) are not shared by all in the academy.

The dependence on staff buy-in also affects the sustainability of the Spine. While most staff at all career stages are happy to contribute, particularly if they feel suitably enabled to do so by the provision of teaching guides, a small number of senior research-active staff opted out of the programme at an early stage. More seriously, the pressures of student recruitment meant that the original design of the programme involving greater input from academic staff had to be abandoned after the first year. For instance, assessment at level 2 is now through peer assessment, rather than tutor assessment; material in four staff-led tutorials is now delivered through two student-led tutorials supported by two cafe style workshops. Paradoxically, the very ways in which the programme relies on a break from past path dependencies mean that its novelty and lack of embeddedness render it vulnerable to pressures to depart from its inherent design when times get tough. The structures and institutional forms which the programme takes (particularly as zero-credit modules) signify dispensability in ways which a true Spine (neither 'bolt-on' outside the department nor 'built-in' at departmental modular level) would not be.

\section{Conclusions}

Although our argument draws on a single case study, we suggest that, seen in the context of the broader literature on undergraduate skills development, and the general context of $\mathrm{HE}$, our conclusions are reasonably generalisable across the sector. We argue there is nothing relevant to our case study that could not be replicated in other disciplinary contexts.

In contrast to Wingate's assertion that small scale, modular and discipline-specific 'built-in' models are the only 'realistic and effective approach for universities' (2006, p.467), a large scale, curriculum-wide intervention, such as our Skills and Values Spine, may be a practical way to achieve a coherent integration of subject-specific knowledge with 'contexttranscendent' skills as part of a broad culture shift among students and staff. To the extent 
that it is generalisable, our case study shows some advantages and benefits of a partnership model. All other things being equal, we suggest the best model for undergraduate skills development is neither 'bolted-on' by 'outsiders' to the academic department, nor 'built-in' to the teaching of a minority of self-selecting academic staff. Rather, it is a blend of the two, which is also created in partnership with students themselves.

But our analysis also reveals barriers to staff and student engagement with the integrated approach and demonstrates that there are significant practical challenges associated with the partnership models. Such partnerships are highly vulnerable to the entrenched organising structures and path dependencies of universities, within which the development of authentic cross-service collaboration, and staff-student partnership, can be challenging. The department-wide culture shift necessary for success is largely dependent on individual staff and students being willing, and having capacity and incentives, to champion the benefits. This dependency raises questions of sustainability and transferability of the model, and suggests that the pace of change is likely to be slow.

At times of crisis or shortage of resources, therefore, the type of partnership model we advocate is probably insufficiently resilient to pressures from university management structures and outside drivers. However, the very fact that the kinds of partnerships we describe are not embedded in existing academic structures and habits is also a key facet of their success. A combination of circumstantial factors, including personal capital, confidence and employment security, is required to sustain such partnerships, precisely because they are not embedded in existing structures, and in some respects pull against dominant narratives, such as narratives of student satisfaction measured as the student experiences HE. Partnerships of this type - like all innovations - are therefore precarious and fragile in nature.

Perhaps Wingate is right: maybe we should advocate 'built-in' models after all? In the final analysis, and on balance, we disagree. To give up on the significant promise of partnership is unnecessarily defeatist. We suggest, therefore, that several key lessons can be drawn from the experience of designing and delivering our Spine. Firstly, the way the model drew on well-established types of learning encounters (especially lectures and tutorials), alongside more 'innovative' and technology-supported learning, together with its badging as a 'module', helps to provide a familiar structure for both student and staff 
participants. Secondly, the viability of this structure depends on the enthusiasm and commitment of empowered staff and student 'champions' who are committed to a shared pedagogical and epistemological approach. Thirdly, at a time of ever-increasing pressure towards short-termism, it is critical to be courageous enough to take the long view. Learning benefits may be invisible to evaluation and come later in the degree programme or beyond $\mathrm{HE}$, long after student feedback on satisfaction has ceased to be captured. Invisibility does not mean learning is not happening. As large institutions, universities are highly path dependent, and change slowly. A major curriculum development will take time to become embedded. With this in mind, it is important to aim high. However, as the overarching vision will inevitably be diluted for all the reasons we have outlined above, celebrate small achievements along the way.

\section{Acknowledgments}

The authors are grateful to Daniel Barrow, Nazma Begum, Louise Bishop, Jess Edwards, Leyla Gayibova, Sarah McCloskey, Sabrina Rahman, Ema Silva-Dobos, Nellie Wanyama, Lee Williams and the many other students and staff at the University of Sheffield who supported and continue to support our curriculum development work. We gratefully acknowledge the support of the Faculty of Social Sciences Curriculum Development Fund, the School of Law, and both University of Sheffield and the University of Sheffield Enterprise Unit.

\section{References}

Biggs, J. (2003) 'Aligning teaching for constructing learning', Higher Education Academy, pp. 1-4.

Brown, N. (forthcoming) 'Partnership in learning: how staff-student collaboration can innovate teaching', submitted to European Journal of Teacher Education.

Brown, R. and Carasso, H. (2013) Everything for sale? The marketisation of UK Higher Education. Abingdon: Routledge. 
Casey, T. (2014) 'Reflective practice in legal education: the stages of reflection', Clinical Law Review, 20(2), pp. 317-354.

Chadha, D. and Nicholls, G. (2006) 'Teaching transferable skills to undergraduate engineering students: recognising the value of embedded and bolt-on approaches', International Journal of Engineering Education, 22(1), pp. 116-122.

Chappie, M. and Tolley, H. (2000) 'Embedding key skills in a traditional university', in Fallows, S. and Steven, C. (eds.) Integrating key skills in higher education: employability, transferable skills and learning for life. London: Kogan Page, pp. 6776.

Dickerson, C., Jarvis, J. and Stockwell, L. (2015) 'Staff-student collaboration: student learning from working together to enhance educational practice in higher education', Teaching in Higher Education, 21(3), pp. 249-265.

Durkin, K. and Main, A. (2002) 'Discipline-based study skills support for first-year undergraduate students', Active Learning in Higher Education, 3(1), pp. 24-39.

Fallows, S. and Steven, C. (2000) 'Building employability skills into the higher education curriculum: a university-wide initiative', Education+training, 42(2), pp. 75-83.

Francis, A. (2015) 'Legal education, social mobility, and employability: possible selves, curriculum intervention, and the role of legal work experience, Journal of Law and Society, 42(2), pp. 173-201.

Ganobcsik-Williams, L. (2004) A report on the teaching of academic writing in UK higher education. Royal Literary Fund.

Gibbs, G. (2013) Learning by doing: a guide to learning and teaching methods. Available at: https://thoughtsmostlyaboutlearning.files.wordpress.com/2015/12/learning-bydoing-graham-gibbs.pdf (Accessed: 25 March 2018). 
Gretton, S. and Raine, D. (2015) 'Student perceptions of embedded employability skills', Higher Education Academy. Available at: https://www.heacademy.ac.uk/system/files/downloads/1.7 sgrettonstudent perceptions of embed employ skills.pdf (Accessed: 8 September 2017).

Gunning, R. (1952) The technique of clear writing. New York: McGraw Hill.

Healey, M., Flint, A. and Harrington, K. (2014) 'Engagement through partnership: students as partners in learning and teaching in higher education', Higher Education Academy. Available at:

https://www.heacademy.ac.uk/system/files/resources/engagement through partner ship.pdf (Accessed: 8 September 2017).

Hervey, T. and Wood, J. (2016) "Now I understand what you were trying to do, I see that this was the best module I had at university': student learning expectations reviewed eight years later', European Journal of Current Legal Issues, 22(3) [Online]. Available at: http://webjcli.org/article/view/505/686 (Accessed: 25 March 2018).

Hinett, K. (2002) Developing reflective practice in legal education. Coventry: UK Centre for Legal Education.

Hockings, C. (2010) Inclusive learning and teaching in higher education: a synthesis of research. Higher Education Academy Report (April).

Kolb, D.A. (2015) Experiential learning: experience as the source of learning and development. $2^{\text {nd }}$ edn. New Jersey: Pearson.

Kolb, D.A. and Fry, R. (1975) 'Toward an applied theory of experiential learning', in Cooper, C. (ed.) Theories of group process. London: John Wiley, pp. 33-57.

Kreber, C. (2010) 'Supporting student learning in the context of diversity, complexity and uncertainty' in Kreber, C. (ed.) The university and its disciplines: teaching and learning within and beyond disciplinary boundaries. Abingdon: Routledge, pp. 3-18. 
Lea, M.R. and Street, B.V. (2006) 'The 'academic literacies' model: theory and applications', Theory into Practice, 45(4), pp. 368-377.

Legal Education and Training Review (2013) Setting standards: the future of legal services education and training regulation in England and Wales. London: Ilex, BSB, SRA.

MacVaugh, J., Jones, A., and Auty, S. (2014) 'Implicit, stand-alone or integrated skills education for undergraduates: a longitudinal analysis of programme outcomes', Journal of Further and Higher Education, 38(6), pp. 755-772.

Molesworth, M., Scullion, R. and Nixon, E. (2010) (eds.) The marketisation of higher education and the student as consumer. Abingdon: Routledge.

Moon, J. (2009) Achieving success through academic assertiveness: real life strategies for today's higher education students. Abingdon: Routledge.

Pierson, P. (2000) 'Increasing returns, path dependence, and the study of politics', American Political Science Review, 94(2), pp. 251-267.

Pierson, P. and Skocpol, T. (2002) 'Historical institutionalism in contemporary political science', in Katznelson, I. and Milner, H.V. (eds.) Political science: the state of the discipline. New York and London: Norton, pp. 693-721.

Poole, G. (2010) 'Academic disciplines: homes or barricades' in Kreber, C. (ed.) The university and its disciplines: teaching and learning within and beyond disciplinary boundaries. Abingdon: Routledge, pp. 50-57.

Pritchard, R.M.O., Klumpp, M. and Teichler, U. (2015) (eds.) Diversity and excellence in higher education. Rotterdam: Sense.

Rué, J., Font, A. and Cebrián, G, (2013) 'Towards high quality reflective learning amongst law undergraduate students', Quality in Higher Education, 19(2), pp. 191-209.

Schön, D.A. (1984) The reflective practitioner: how professionals think in action. New York: Basic Books. 
Stevenson, J. and Clegg, S. (2011) 'Possible selves: students orientating themselves towards the future through extracurricular activity', British Educational Research Journal, 37(2), pp. 231-246.

Thies, L.C. (2012) 'Increasing student participation and success: collaborating to embed academic literacies into the curriculum', Journal of Academic Language and Learning, 6(1), A15-A31.

Wingate, U. (2006) 'Doing away with 'study skills”, Teaching in Higher Education, 11(4), pp. 457-469.

\section{Author details}

James Cairns was Research Assistant on the project and Corporate and Commercial Law LLM student. James has interests in curriculum design and legal studies, and is seeking a career as a criminal barrister with a focus on corporate crime.

Tamara Hervey FAcSS PFHEA is Jean Monnet Professor of EU Law at the University of Sheffield. Her interests include European Union health law, legal research methodologies, equality and diversity law, and legal education.

Oliver Johnson is an Academic Skills Development Adviser at 301 Student Skills and Development Centre at the University of Sheffield. He is a Doctor of Soviet art history and a specialist in study skills and student learning. 